\title{
Sitting time and occupational and recreational physical activity in relation to the risk of esophageal squamous cell carcinoma
}

This article was published in the following Dove Press journal:

OncoTargets and Therapy

27 September 2017

Number of times this article has been viewed

\author{
Pengxiang Chen' \\ Qingxu Song' \\ Jie $\mathrm{Han}^{2}$ \\ Huapu $\mathrm{Xu}^{3}$ \\ Tong Chen ${ }^{4}$ \\ Jiaqi $\mathrm{Xu}^{5}$ \\ Yufeng Cheng'
}

'Department of Radiation Oncology, Qilu Hospital of Shandong University, ${ }^{2}$ Department of Radiation Oncology, Shandong Cancer Hospital and Institute, Shandong University, Jinan, ${ }^{3}$ Department of Oncology, Pingyi Hospital of Traditional Chinese Medicine, Pingyi, ${ }^{4}$ Department of Oncology, Union Hospital, Tongji Medical College, Huazhong University of Science and Technology, Wuhan, ${ }^{5}$ Department of Orthopaedics, Sir Run Run Shaw Hospital, School of Medicine, Zhejiang University, Hangzhou, People's Republic of China
Backgrounds: Sitting time and physical activity are associated with cancer risk; however, their roles in the development of esophageal squamous cell carcinoma (ESCC) are inconclusive. This study aimed to investigate the effects of total sitting time, occupational activity time (OAT), and recreational activity time (RAT) on ESCC risk.

Methods: Five hundred fifty-seven ESCC patients and 543 healthy controls matched by sex and age were recruited for this study. Conditional logistic regression was performed to obtain odds ratios (ORs) and 95\% confidence intervals (CIs).

Results: Longer total sitting time (adjusted OR [AOR] 2.54, 95\% CI 1.58-4.09) and longer OAT (AOR 2.90, 95\% CI 2.11-3.99) were associated with higher ESCC risk, while longer RAT (AOR 0.27, 95\% CI 0.19-0.38) could reduce ESCC risk. When the body mass index was incorporated into the multivariable models, the results changed slightly. In risk estimation according to sex, the same trends were observed in both men and women. Furthermore, longer RAT could completely or partially diminish the impacts of longer sitting time and OAT on increasing ESCC risk.

Conclusion: Long sitting time and long OAT can increase the risk of ESCC, while long RAT is significantly associated with decreased ESCC risk.

Keywords: esophageal squamous cell carcinoma, sitting time, physical activity, cancer epidemiology, carcinogenesis

\section{Introduction}

According to global cancer data in 2012, there were estimated 455,800 newly diagnosed esophageal cancer (EC) patients and 400,200 EC-associated deaths worldwide. ${ }^{1}$ In high-risk regions, esophageal squamous cell carcinoma (ESCC) accounted for $90 \%$ of all EC cases. ${ }^{2}$ Alcohol consumption, tobacco smoking, and low intake of fruits and vegetables are common risk factors of ESCC. ${ }^{3}$ However, the etiology of ESCC remains uncertain and exploring possible risk factors of ESCC is in urgent need.

Extensive studies demonstrated that physical activity can reduce the risk of heart diseases, cancers, and all-cause mortality. ${ }^{4}$ Physical activity has also been reported to be associated with decreased incidence and mortality of various cancers. ${ }^{5,6}$ Studies have implied an inverse relationship between total physical activity and EC risk. ${ }^{7-9}$ Physical activity can be classified into various types, such as occupational activity performed at work and recreational activity done for fitness or health. ${ }^{10,11}$ Studies focusing on the association between ESCC risk and different activity types are limited and show inconclusive results. ${ }^{7,9,12,13}$ 
Sitting time, associated with cardiovascular diseases, various cancers, and higher mortality, is significantly different from the physical inactivity. ${ }^{14}$ One adult's sitting time is relatively independent of the time spent on physical activity. ${ }^{15}$ Sitting time has attracted a lot attention in cancer prevention. A meta-analysis demonstrated a positive association between sitting time and the risk of colon and endometrial cancers. ${ }^{16}$ A study in one cohort found that long sitting time contributed to high total cancer risk in women. ${ }^{17}$ To our best of knowledge, only one study investigated the relationship between total sitting time and ESCC, with no statistical correlations between 215 ESCC patients and health controls. ${ }^{12}$

Based on the above information, we conducted the present case-control study to investigate the impact of moderate to vigorous occupational and recreational activity time (RAT) and total sitting time on ESCC risk. Additionally, whether the impact of these factors relied on obesity was assessed by adjusting for body mass index (BMI). For the first time, we explored the adjusted impacts of total sitting time, occupational activity time (OAT), and RAT on ESCC risk by adding them into one multivariable model.

\section{Methods}

\section{Case and control selection}

From July 2015 to January 2017, 598 patients newly pathologically diagnosed with ESCC at Qilu Hospital of Shandong University, Shandong Cancer Hospital and Institute, Wuhan Union Hospital, Sir Run Run Shaw Hospital, and Pingyi Hospital of Traditional Chinese Medicine were invited to participate in this study. The exclusion criteria were as follows: 1) one refused our invitation; 2) one had a family history of tumors of the digestive system; 3 ) one had locomotor system diseases; and 4) one reported that he/she could not recall the status before ESCC diagnosis. The participation rate was $93 \%$, and 557 cases were finally included.

A total of 543 age- and sex-matched (frequency matching) controls were recruited at $\sim 1: 1$ ratio (the response rate among controls was 95\%). These controls were composed of healthy people who arrived at hospital for health checkups (68\%) and other patients whose diagnoses were not related to ESCC, including dermatologic disorders (18\%), hernias (6\%), acute urinary inflammation (4\%), and rhinitis (4\%). Specifically, considering China is a large agricultural country and the life factors may differ notably between farmers and nonfarmers, we had balanced the proportion of farmers between ESCC patients and controls when recruiting subjects. The proportion of farmers was 55\% in cases and 58\% in controls. The current study was approved by the Ethics Review Committee of each participating hospital and was conducted in accordance with the ethical standards of the 1964 Declaration of Helsinki and its later amendments. Written informed consent was obtained from every participant in our study.

\section{Data collection}

A structured questionnaire including height $(\mathrm{cm})$, weight (kg), total sitting time (hours/day), OAT (hours/day), RAT (hours/week), smoking status, drinking frequency (times/month), and dietary habit was used to collect the relevant information. Our trained staff performed face-to-face interviews with participants to instruct them to report the status before ESCC diagnosis.

The total sitting time was defined as the total time spent on sitting per day by the patients over 12 months prior to the development of ESCC $(<1,1-3,3-5,5-7$, and $\geq 7$ hours/day according to the questionnaire). The duration of physical activity was collected according to various intensities and types. This study only included the time spent on moderate to vigorous physical activities that required effort equivalent to that of a brisk walk or that could lead to a recognizable increase in breathing, heart rate, and sweating. ${ }^{10,18}$ OAT was defined as the average time spent on moderate to vigorous physical activities during working hours per day in adult life, such as custodial work, farming, machine repair, forestry, and construction. RAT was defined as the time spent per week on moderate to vigorous physical activities for recreation or health, such as walking and running, leisurely bicycling, swimming, and playing baseball, basketball, and tennis.

BMI was calculated by dividing weight $(\mathrm{kg})$ by height squared $\left(\mathrm{m}^{2}\right)$. According to the World Health Organization data, participants were assigned into the following three groups by BMI: $<18.5,18.5-24.9$, and $\geq 25.0 \mathrm{~kg} / \mathrm{m}^{2} .{ }^{19}$ The participants were separated according to their smoking status as never, former, and current smokers. Participants who never smoked or smoked no $>100$ cigarettes during their lifetime were classified as never smokers. Former smokers included those who had quit smoking at least 1 year before the diagnosis of ESCC. Current smokers included individuals who had quit smoking $<1$ year before diagnosis or were still smoking at the time of the study. ${ }^{20}$ The drinking frequency was classified as never, occasional, and often. ${ }^{21}$ Individuals who drank 0-1 times per month were defined as never drinkers. "Occasional drinking" referred to drinking 2-8 times/month, while drinking $\geq 9$ times/month was classified as "often drinking" in this study. Daily consumption of moldy food, hot food, fried food, or pickled vegetables was listed as a special dietary habit. 
Finally, the collected information was categorized as follows: total sitting time (short: $<3$ hours; moderate: 3-6 hours; and long: $\geq 7$ hours), OAT (short: $\leq 2$ hours; moderate: $2-4$ hours; and long: $>4$ hours), RAT (no: 0 hours; short: $\leq 2$ hours; and long: $>2$ hours), smoking status (never/ former/current), drinking frequency (never/occasional/often), and dietary habits (normal/special).

\section{Statistical analysis}

$\chi^{2}$ test and Student's $t$-test were adopted in the analyses of categorical variables and numerical variables of the cases and controls, respectively. Associations between variables and ESCC risk were measured with odds ratios (ORs) and 95\% confidence intervals (CIs) by conditional logistic regression models matched on age and sex. The multivariable models were adjusted for potential confounding factors, including total sitting time, OAT, RAT, smoking status, drinking frequency, and dietary habit, with or without BMI. Data were analyzed by the STATA software (Version 12; StataCorp LP, College Station, TX, USA). A two-sided $P$-value of $<0.05$ was considered statistically significant.

\section{Results}

Five hundred fifty-seven ESCC patients and 543 sex- and age-matched control individuals were included in this casecontrol study. Table 1 shows the baseline characteristics of the subjects. The mean age \pm standard deviation was $61.3 \pm 9.9$ and $61.5 \pm 10.5$ years in the ESCC patients and controls, respectively. The percentage of current smokers, frequent drinkers, and individuals with special dietary habits was significantly higher among the ESCC patients than the controls (all $P<0.001$ ). Compared to the controls, both sitting time $(P=0.04)$ and OAT $(P<0.001)$ were longer, while RAT $(P<0.001)$ was shorter in the ESCC patients.

The risks of ESCC in relation to sitting time, OAT, RAT, and other factors are exhibited in Table 2. The adjusted OR (AOR) of ESCC was 1.47 (95\% CI 1.08-2.00) and 2.54 (95\% CI 1.58-4.09) for subjects with moderate and long sitting time, respectively, compared to short sitting time. Longer OAT was associated with higher ESCC risk (for moderate OAT, AOR 1.63, 95\% CI 1.04-2.57; for long OAT, AOR 2.90, 95\% CI 2.11-3.99). Relative to no RAT, ESCC risk decreased with the length of RAT (for $\leq 2$ hours, AOR $0.51,95 \%$ CI $0.36-0.74$; for $>2$ hours, AOR $0.27,95 \% \mathrm{CI}$ 0.19-0.38). Compared to nonsmokers, the current smokers displayed $\sim 2.65$-fold ESCC risk (95\% CI 1.81-3.84), while often drinkers exhibited $\sim 3.10$-fold ESCC risk $(95 \%$ CI 2.03-4.72). The AOR of individuals with special dietary
Table I Characteristics of ESCC patients and controls

\begin{tabular}{|c|c|c|c|}
\hline Characteristics & $\begin{array}{l}\text { ESCC } \\
(n=557)\end{array}$ & $\begin{array}{l}\text { Controls } \\
(n=543)\end{array}$ & $P$-value \\
\hline \multicolumn{4}{|l|}{ Sex } \\
\hline Male & $456(82.0 \%)$ & 435 (80.0\%) & 0.49 \\
\hline Female & $101(18.0 \%)$ & $108(20.0 \%)$ & \\
\hline \multicolumn{4}{|l|}{ Age (years) } \\
\hline$<40$ & 12 (2.2\%) & II (2.0\%) & 0.42 \\
\hline $40-49$ & 55 (9.9\%) & $63(11.6 \%)$ & \\
\hline $50-59$ & 155 (27.8\%) & I5I (27.8\%) & \\
\hline $60-69$ & 225 (40.4\%) & $193(35.6 \%)$ & \\
\hline$\geq 70$ & $110(19.7 \%)$ & 125 (23.0\%) & \\
\hline \multicolumn{4}{|l|}{ Smoking status } \\
\hline Never & 191 (34.3\%) & $370(68.1 \%)$ & $<0.001$ \\
\hline Former & $63(11.3 \%)$ & $66(12.2 \%)$ & \\
\hline Current & 303 (54.4\%) & 107 (19.7\%) & \\
\hline \multicolumn{4}{|c|}{ Drinking frequency (times/month) } \\
\hline Never & 177 (31.8\%) & $321(59.1 \%)$ & $<0.001$ \\
\hline Occasional & $123(22.1 \%)$ & 154 (28.4\%) & \\
\hline Often & 257 (46.1\%) & $68(12.5 \%)$ & \\
\hline \multicolumn{4}{|l|}{ BMI $\left(\mathrm{kg} / \mathrm{m}^{2}\right)$} \\
\hline$<18.5$ & $22(3.9 \%)$ & $23(4.2 \%)$ & 0.97 \\
\hline $18.5-24.9$ & 347 (62.3\%) & $338(62.3 \%)$ & \\
\hline$\geq 25.0$ & $188(33.8 \%)$ & $182(33.5 \%)$ & \\
\hline \multicolumn{4}{|l|}{ Dietary habit } \\
\hline Normal & 309 (55.5\%) & 429 (79.0\%) & $<0.001$ \\
\hline Special & $248(44.5 \%)$ & $114(21.0 \%)$ & \\
\hline \multicolumn{4}{|l|}{ Sitting time (hours/day) } \\
\hline$<3$ & $219(39.3 \%)$ & $250(46.0 \%)$ & 0.04 \\
\hline $3-6$ & 259 (46.5\%) & $236(43.5 \%)$ & \\
\hline$\geq 7$ & 79 (14.2\%) & 57 (10.5\%) & \\
\hline $\begin{array}{l}\text { Occupational activity time } \\
\text { (hours/day) }\end{array}$ & $4.8 \pm 3.7$ & $2.7 \pm 2.9$ & $<0.001$ \\
\hline $\begin{array}{l}\text { Recreational activity time } \\
\text { (hours/week) }\end{array}$ & $2.2 \pm 3.7$ & $3.9 \pm 4.2$ & $<0.001$ \\
\hline
\end{tabular}

Note: Values are mean \pm SD or frequency (\%).

Abbreviations: BMI, body mass index; ESCC, esophageal squamous cell carcinoma.

habits was 2.19 (95\% CI 1.61-2.99) relative to the individuals with normal dietary habits.

Furthermore, considering the potential relationship between BMI and sitting as well as physical activity, we added BMI to our multivariable models. Nevertheless, when BMI was included, the risk assessment for sitting time, OAT, and RAT remained statistically significant, whereas for smoking status, drinking frequency, and dietary habit, the AOR changed very slightly.

Because the incidence of EC and lifestyle differed significantly between men and women, ${ }^{1,22}$ we performed risk estimation according to sex (Table 3 ). In both men and women, longer sitting time, longer OAT, smoking, and special dietary habits were associated with high ESCC risk, while longer RAT was related to reduced ESCC risk. However, no association between drinking and risk of ESCC was found in women. 
Table 2 OR of ESCC according to sitting time, occupational activity time, recreational activity time, and other risk factors

\begin{tabular}{|c|c|c|c|c|c|}
\hline Subjects & $\operatorname{ESCC}(n=557)$ & Controls $(n=543)$ & Crude OR $(95 \% \mathrm{Cl})$ & Adjusted OR ${ }^{\mathrm{a}}(95 \% \mathrm{Cl})$ & Adjusted $\mathrm{OR}^{\mathrm{b}}(95 \% \mathrm{Cl})$ \\
\hline \multicolumn{6}{|c|}{ Sitting time (hours/day) } \\
\hline$<3$ & 219 & 250 & 1.00 (reference) & I.00 (reference) & 1.00 (reference) \\
\hline $3-6$ & 259 & 236 & $1.25(0.97-1.61)$ & $1.47(1.08-2.00)$ & $1.49(1.09-2.02)$ \\
\hline$\geq 7$ & 79 & 57 & $1.58(1.08-2.33)$ & $2.54(1.58-4.09)$ & $2.56(1.59-4.12)$ \\
\hline \multicolumn{6}{|c|}{ Occupational activity time (hours/day) } \\
\hline$\leq 2$ & 205 & 347 & 1.00 (reference) & I.00 (reference) & $\mathrm{I} .00$ (reference) \\
\hline $2-4$ & 67 & 64 & $1.77(1.21-2.60)$ & $1.63(1.04-2.57)$ & $1.62(1.03-2.55)$ \\
\hline$>4$ & 285 & 132 & $3.66(2.79-4.78)$ & $2.90(2.11-3.99)$ & $2.90(2.11-4.00)$ \\
\hline \multicolumn{6}{|c|}{ Recreational activity time (hours/week) } \\
\hline 0 & 270 & 109 & 1.00 (reference) & 1.00 (reference) & 1.00 (reference) \\
\hline$\leq 2$ & 146 & 154 & $0.38(0.28-0.53)$ & $0.5 \mathrm{I}(0.36-0.74)$ & $0.52(0.36-0.74)$ \\
\hline$>2$ & $|4|$ & 280 & $0.20(0.15-0.28)$ & $0.27(0.19-0.38)$ & $0.27(0.19-0.38)$ \\
\hline \multicolumn{6}{|l|}{ Smoking status } \\
\hline Never & 191 & 370 & $\mathrm{I} .00$ (reference) & I.00 (reference) & 1.00 (reference) \\
\hline Former & 63 & 66 & $1.85(1.26-2.72)$ & $1.66(1.01-2.72)$ & $1.64(1.00-2.70)$ \\
\hline Current & 303 & 107 & $5.49(4.14-7.27)$ & $2.64(1.81-3.84)$ & $2.66(1.83-3.87)$ \\
\hline \multicolumn{6}{|c|}{ Drinking frequency (times/month) } \\
\hline Never & 177 & 321 & 1.00 (reference) & 1.00 (reference) & 1.00 (reference) \\
\hline Occasional & 123 & 154 & $1.45(1.07-1.96)$ & $0.98(0.66-1.45)$ & $0.98(0.66-1.45)$ \\
\hline Often & 257 & 68 & $6.85(4.96-9.48)$ & $3.10(2.03-4.72)$ & $3.12(2.05-4.76)$ \\
\hline \multicolumn{6}{|l|}{ Dietary habit } \\
\hline Normal & 309 & 429 & 1.00 (reference) & I.00 (reference) & 1.00 (reference) \\
\hline Special & 248 & 114 & $3.04(2.32-3.94)$ & $2.19(1.61-2.99)$ & $2.19(1.61-2.99)$ \\
\hline
\end{tabular}

Notes: aln the multivariate model including sitting time, occupational activity time, recreational activity time, smoking status, drinking frequency, and dietary habits. ${ }^{\circ} \mathrm{n}$ the multivariate model including sitting time, occupational activity time, recreational activity time, smoking status, drinking frequency, dietary habits, and BMI.

Abbreviations: $\mathrm{BMI}$, body mass index; $\mathrm{Cl}$, confidence interval; ESCC, esophageal squamous cell carcinoma; OR, odds ratio.

Table 3 OR of ESCC for sitting time, occupational activity time, recreational activity time, and other risk factors according to sex

\begin{tabular}{|c|c|c|c|c|c|c|}
\hline \multirow[t]{2}{*}{ Subjects } & \multicolumn{3}{|l|}{ Men } & \multicolumn{3}{|l|}{ Women } \\
\hline & $\begin{array}{l}\text { ESCC } \\
(n=456)\end{array}$ & $\begin{array}{l}\text { Controls } \\
(n=435)\end{array}$ & $\begin{array}{l}\text { Adjusted OR } \\
(95 \% \mathrm{Cl})\end{array}$ & $\begin{array}{l}\text { ESCC } \\
(n=\mid 01)\end{array}$ & $\begin{array}{l}\text { Controls } \\
(n=108)\end{array}$ & $\begin{array}{l}\text { Adjusted OR } \\
(95 \% \mathrm{Cl})\end{array}$ \\
\hline \multicolumn{7}{|c|}{ Sitting time (hours/day) } \\
\hline$<3$ & 185 & 182 & 1.00 (reference) & 34 & 68 & 1.00 (reference) \\
\hline $3-6$ & 208 & 206 & $1.19(0.84-1.69)$ & 51 & 30 & $4.13(1.94-8.78)$ \\
\hline$\geq 7$ & 63 & 47 & $1.90(1.11-3.26)$ & 16 & 10 & $8.18(2.68-24.93)$ \\
\hline \multicolumn{7}{|c|}{ Occupational activity time (hours/day) } \\
\hline$\leq 2$ & 169 & 278 & 1.00 (reference) & 36 & 69 & 1.00 (reference) \\
\hline $2-4$ & 52 & 54 & $1.31(0.78-2.20)$ & 15 & 10 & $2.93(0.96-8.94)$ \\
\hline$>4$ & 235 & 103 & $2.78(1.93-3.99)$ & 50 & 29 & $3.66(1.71-7.82)$ \\
\hline \multicolumn{7}{|c|}{ Recreational activity time (hours/week) } \\
\hline 0 & 223 & 81 & 1.00 (reference) & 47 & 28 & 1.00 (reference) \\
\hline$\leq 2$ & 122 & 128 & $0.52(0.34-0.78)$ & 24 & 26 & $0.56(0.22-1.42)$ \\
\hline$>2$ & 111 & 226 & $0.28(0.19-0.41)$ & 30 & 54 & $0.22(0.10-0.5 \mathrm{I})$ \\
\hline \multicolumn{7}{|l|}{ Smoking status } \\
\hline Never & 113 & 271 & 1.00 (reference) & 78 & 99 & 1.00 (reference) \\
\hline Former & 58 & 59 & $1.89(I . I I-3.2 I)$ & 5 & 7 & $1.17(0.24-5.76)$ \\
\hline Current & 285 & 105 & $2.76(1.85-4.12)$ & 18 & 2 & $12.92(2.25-54.07)$ \\
\hline \multicolumn{7}{|c|}{ Drinking frequency (times/month) } \\
\hline Never & 100 & 229 & 1.00 (reference) & 77 & 92 & 1.00 (reference) \\
\hline Occasional & 110 & 141 & $1.25(0.8 \mathrm{I}-1.93)$ & 13 & 13 & $0.66(0.21-2.07)$ \\
\hline Often & 246 & 65 & $4.02(2.57-6.28)$ & 11 & 3 & $0.97(0.15-6.31)$ \\
\hline \multicolumn{7}{|l|}{ Dietary habit } \\
\hline Normal & 253 & 341 & 1.00 (reference) & 56 & 88 & 1.00 (reference) \\
\hline Special & 203 & 94 & $2.02(1.42-2.88)$ & 45 & 20 & $3.11(1.48-6.54)$ \\
\hline
\end{tabular}

Note: In the multivariate model including sitting time, occupational activity time, recreational activity time, smoking status, drinking frequency, and dietary habits. Abbreviations: $\mathrm{Cl}$, confidence interval; ESCC, esophageal squamous cell carcinoma; OR, odds ratio. 
Table 4 AORs of ESCC for sitting time and occupational activity time according to recreational activity time

\begin{tabular}{|c|c|c|c|c|c|c|}
\hline \multirow[t]{3}{*}{ Subjects } & \multicolumn{6}{|c|}{ Recreational activity time (hours/week) } \\
\hline & \multicolumn{2}{|l|}{0} & \multicolumn{2}{|l|}{$\leq 2$} & \multicolumn{2}{|l|}{$>2$} \\
\hline & $\operatorname{AOR}^{\mathrm{a}}(95 \% \mathrm{Cl})$ & $P$-value & $\operatorname{AOR}^{a}(95 \% \mathrm{Cl})$ & $P$-value & $\operatorname{AOR}^{a}(95 \% \mathrm{Cl})$ & $P$-value \\
\hline \multicolumn{7}{|c|}{ Sitting time (hours/day) } \\
\hline$<3$ & 1.00 (reference) & & $\mathrm{I} .00$ (reference) & & 1.00 (reference) & \\
\hline $3-6$ & $2.10(1.2 \mathrm{I}-3.62)$ & 0.008 & $1.53(0.85-2.76)$ & 0.16 & $1.11(0.67-1.83)$ & 0.68 \\
\hline$\geq 7$ & $6.92(2.42-19.80)$ & $<0.001$ & $2.80(1.01-7.74)$ & 0.05 & I.48 (0.75-2.92) & 0.25 \\
\hline \multicolumn{7}{|c|}{ Occupational activity time (hours/day) } \\
\hline$\leq 2$ & 1.00 (reference) & & 1.00 (reference) & & 1.00 (reference) & \\
\hline $2-4$ & $2.43(1.03-5.72)$ & 0.04 & I.7I (0.70-4.18) & 0.24 & $1.16(0.57-2.37)$ & 0.68 \\
\hline$>4$ & $3.72(2.10-6.58)$ & $<0.001$ & $4.98(2.60-9.54)$ & $<0.001$ & $1.88(1.13-3.13)$ & 0.01 \\
\hline
\end{tabular}

Note: aln the multivariate model, including sitting time, occupational activity time, smoking status, drinking frequency, and dietary habits. Abbreviations: AORs, adjusted odds ratios; $\mathrm{Cl}$, confidence interval; ESCC, esophageal squamous cell carcinoma.

Additionally, we performed risk estimation for ESCC based on sitting time and OAT according to the groups stratified by RAT (Table 4). In the group with no RAT, moderate/ long sitting time and moderate/long OAT (all $P<0.05$ ) were significantly associated with higher ESCC risk, especially long sitting time (AOR 6.92, 95\% CI 2.42-19.80). For RAT $\leq 2$ hours, the individuals with long sitting time (AOR 2.80, 95\% CI 1.01-7.74) and long OAT (AOR 4.98, 95\% CI 2.60-9.54) had a higher risk of ESCC. For individuals with long RAT ( $>2$ hours), only long OAT (AOR 1.88, 95\% CI 1.13-3.13) displayed a statistical relationship with high ESCC risk, but its effect was noticeably weakened compared to those with no RAT (AOR changed from 3.72 to 1.88).

\section{Discussion}

Dominant roles of lifestyle factors in the pathogenesis of ESCC have been previously demonstrated. ${ }^{23}$ This study showed the impacts of long sitting time and OAT in increasing ESCC risk and the effects of long RAT in decreasing ESCC risk in both sexes. The trends of those factors in influencing ESCC risk remained statistically stable when adjusting for BMI. Furthermore, we found that the effect of sitting time on ESCC risk could be completely eliminated and the effect of OAT could be partially diminished by long RAT.

Previous studies have suggested the association between more physical activity and lower risk of various cancers, including esophageal adenocarcinoma (EAC). ${ }^{8,24,25}$ Interestingly, recreational activity was found to act as a protective factor against EC, whereas occupational activity could increase the risk of EC. ${ }^{26,27}$

Data on the relationship between physical activity and ESCC risk are very limited and variable. Etemadi et $\mathrm{al}^{13}$ reported that reduced professional physical activity in childhood or early adult life could increase ESCC risk only in women. A study in an Indian cohort demonstrated a strong association between strenuous occupational activity and high ESCC risk, ${ }^{27}$ whereas another study reported negative result in ESCC. ${ }^{7}$ Our study found that longer RAT was clearly associated with lower ESCC risk, while longer OAT led to an increased ESCC risk, which is in line with previous studies. In the stratification analysis according to sex, the results were also positive in both men and women and it appeared that the impacts of OAT and RAT were stronger in women. These findings suggested that the impacts of physical activity on ESCC risk differed according to the type of activity.

Our analyses showed that longer RAT was associated with lower BMI $(P=0.04)$. And one hypothesis is that physical activity can prevent weight gain and thus reduce cancer risk. ${ }^{28,29}$ However, when BMI was incorporated in the model, the risk of ESCC in relation to RAT and OAT changed only slightly, suggesting that the roles of different physical activities were relatively independent of BMI. There are several potential mechanisms to explain our findings. For instance, more physical activity was shown to be associated with a reduced risk of gastresophageal reflux disease and, thus, physical activity might decrease the risk of ESCC..$^{30,31}$ In addition, physical activity has been linked with cancer prevention via other mechanisms, including inhibition of chronic inflammation and regulation of circulation and other factors such as bowel transit time, immune function, and DNA repair. ${ }^{32-34}$ As confirmed, natural killer (NK) cells play critical roles in killing cancer cells through the direct cytotoxicity, as well as activating T cells and M1 macrophages. ${ }^{35,36}$ Exercise can exactly induce a crosstalk of muscle-to-immune cells to regulate immune system via promoting the release of myokines, thus enhancing the activation and function of NK cells to prevent tumorigenesis. ${ }^{37}$ 
The differential effects of recreational and occupational activities need to be further elucidated. It is likely that individuals who had longer RAT might have more opportunities to communicate with friends and family under relaxed circumstances, making it easier to maintain a good mood and immune state. However, individuals who spent more time on occupational activities may have a poorer socioeconomic status and greater stress in life, which could be related to higher ESCC risk. ${ }^{27,38}$ As Ma et al ${ }^{39}$ reported, stress could induce apoptosis of NK cells and markedly decrease their activity, which might facilitate the growth of cancer cells. Unfortunately, we did not obtain the data on detailed socioeconomic parameters.

A previous study assessed the relationship between sedentary time and cancer risk but provided little evidence for the particular cancer types. ${ }^{16}$ Patel et al found that the total risk increased when the duration of leisure time spent on sitting was prolonged for various cancers in women, including multiple myeloma and breast and ovarian cancers. ${ }^{17}$ The only study analyzing the relationship between total sitting time and ESCC reported a negative association, although it demonstrated that increased sitting time was related to high EAC risk. ${ }^{12}$ Inconsistent with the findings in this cohort, our results supported that long total sitting time was associated with increased ESCC risk in both sexes and especially in women.

In our analysis, subjects with longer sitting time tended to have higher $\mathrm{BMI}(P=0.08)$ without statistical significance and AOR of ESCC for sitting time changed slightly when BMI included. Shen et $\mathrm{al}^{40}$ also reported that sedentary behavior was associated with increased risk of various cancers independent of energy intake and BMI. Therefore, other potential mechanisms exist. First, sedentary behavior has been implied to be related to metabolic dysfunction. ${ }^{41,42}$ Studies have demonstrated the association of metabolic dysfunction with EC. ${ }^{43,44}$ Second, sitting time can change the levels of sex hormones, further affecting body's immune function. ${ }^{45}$ Third, excessive sitting can stimulate the release of various inflammatory mediators, such as interleukin-6 and tumor necrosis factor- $\alpha$, which are recognized as risk predictors of cancer. ${ }^{46}$ Undoubtedly, the mechanisms are complex and further studies need to be performed.

To verify whether the impact of long sitting time and OAT on increasing ESCC risk could be diminished by RAT, we further performed stratification analysis according to the various RAT groups. Interestingly, longer sitting time was not associated with ESCC risk when RAT $>2$ hours, suggesting that long RAT could eliminate the negative effects of sitting on ESCC development. In addition, AOR of ESCC was partially diminished in subjects with longer OAT when their RAT was $>2$ hours. This indicated that longer RAT showed protective roles for individuals with longer sitting time or longer OAT.

Both smoking and drinking have been suggested as important risk factors in ESCC in our study, which is identical with previous studies. ${ }^{47}$ However, our results showed that the drinking frequency was not associated with ESCC risk in women. It is difficult to explain why drinking was not a risk factor in women, and we are unconfident with this result, as it may due to the small number of women in this study. Individuals who had special dietary habit were also found to undergo higher ESCC risk, which was consistent with other reports. ${ }^{48}$

The strength of the current study is that it included age- and sex-matched control subjects at $\sim 1: 1$ ratio, which strengthened the comparability and reliability of the results. Additionally, we enrolled participants from multiple cities in both northern and southern areas of China, thereby improving the representation of the samples. This study has some limitations. First, it is a retrospective study, which may have limited the accuracy of the information. Second, the sample number is relatively small, especially the number of female participants. This limitation may render some analyses unreliable, but our main results were highly significant and in agreement with the overall analysis. Third, information on the socioeconomic status and occupational exposures including carcinogenic dust and fumes could not be obtained, which are potential confounding factors and may influence the results to an extent. Fourth, 12 months definition used during information collection was intended to control recall bias, but it might not be long enough for the study. Large-scale prospective studies are needed to confirm our findings.

\section{Conclusion}

This study demonstrates that in both sexes, long total sitting time and OAT can increase risks of ESCC, while long RAT is associated with decreased ESCC risk. Risk estimation for the three factors remained significant when the model was adjusted to include BMI. Furthermore, long RAT ( $>2$ hours/week) can be an effective way to reduce ESCC risk caused by long sitting time or long OAT. This study provides more indicative evidence for broadening the etiology of ESCC. And total sitting time and physical activity time may be significant behavioral factors in ESCC risk, which can be corrected in daily life.

\section{Acknowledgments}

We are grateful to Dr Nashang Zhang, Xiaoli Zhang, Detian Xie, Yue Peng, Renchang Zhao, Jian Wang, 
Xiaodong Li, Changtong Gao, Yida Li, Yan Qu, Ziying Jiang, Ning Zhang, Xiaoyi Du, Zhenhui Du, Qinzheng Bai, and Yunan Hou for their contributions to data collection. We also thank Cong Wang, Lihui Han, and Jianfeng Cui for their assistance in our statistical analyses. This study was supported by the National Natural Science Foundation of China (no 81572958), Science and Technology Development Planning Project of Shandong Province (2014GSF118058), Natural Science Foundation of Shandong Province (ZR2015HQ024), and Science Foundation of Qilu Hospital of Shandong University (2016QLQN35).

\section{Disclosure}

The authors report no conflicts of interest in this work.

\section{References}

1. Torre LA, Bray F, Siegel RL, Ferlay J, Lortet-Tieulent J, Jemal A. Global cancer statistics, 2012. CA Cancer J Clin. 2015;65(2):87-108.

2. Lu CL, Lang HC, Luo JC, et al. Increasing trend of the incidence of esophageal squamous cell carcinoma, but not adenocarcinoma, in Taiwan. Cancer Causes Control. 2010;21(2):269-274.

3. Schweigert M, Dubecz A, Stein HJ. Oesophageal cancer - an overview. Nat Rev Gastroenterol Hepatol. 2013;10(4):230-244.

4. Arem H, Moore SC, Patel A, et al. Leisure time physical activity and mortality: a detailed pooled analysis of the dose-response relationship. JAMA Intern Med. 2015;175(6):959-967.

5. Singh PP, Singh S. Statins are associated with reduced risk of gastric cancer: a systematic review and meta-analysis. Ann Oncol. 2013; 24(7):1721-1730.

6. Boyle T, Keegel T, Bull F, Heyworth J, Fritschi L. Physical activity and risks of proximal and distal colon cancers: a systematic review and meta-analysis. J Natl Cancer Inst. 2012;104(20):1548-1561.

7. Leitzmann MF, Koebnick C, Freedman ND, et al. Physical activity and esophageal and gastric carcinoma in a large prospective study. Am J Prev Med. 2009;36(2):112-119.

8. Winzer BM, Paratz JD, Reeves MM, Whiteman DC. Exercise and the prevention of oesophageal cancer (EPOC) study protocol: a randomized controlled trial of exercise versus stretching in males with Barrett's oesophagus. BMC Cancer. 2010;10:292.

9. Singh S, Devanna S, Edakkanambeth VJ, Murad MH, Iyer PG. Physical activity is associated with reduced risk of esophageal cancer, particularly esophageal adenocarcinoma: a systematic review and meta-analysis. BMC Gastroenterol. 2014;14:101.

10. Kushi LH, Doyle C, McCullough M, et al. American Cancer Society guidelines on nutrition and physical activity for cancer prevention. $C A$ Cancer J Clin. 2012;62(1):30-67.

11. Hallal PC, Andersen LB, Bull FC, et al; Lancet Physical Activity Series Working Group. Global physical activity levels: surveillance progress, pitfalls, and prospects. Lancet. 2012;380(9838):247-257.

12. Cook MB, Matthews CE, Gunja MZ, Abid Z, Freedman ND, Abnet CC. Physical activity and sedentary behavior in relation to esophageal and gastric cancers in the NIH-AARP cohort. PLoS One. 2013;8(12):e84805.

13. Etemadi A, Golozar A, Kamangar F, et al. Large body size and sedentary lifestyle during childhood and early adulthood and esophageal squamous cell carcinoma in a high-risk population. Ann Oncol. 2012;23(6):1593-1600.

14. Biswas A, Oh PI, Faulkner GE, et al. Sedentary time and its association with risk for disease incidence, mortality, and hospitalization in adults: a systematic review and meta-analysis. Ann Intern Med. 2015; 162(2):123-132.
15. Craft LL, Zderic TW, Gapstur SM, et al. Evidence that women meeting physical activity guidelines do not sit less: an observational inclinometry study. Int J Behav Nutr Phys Act. 2012;9:122.

16. Schmid D, Leitzmann MF. Television viewing and time spent sedentary in relation to cancer risk: a meta-analysis. J Natl Cancer Inst. 2014;106(7):dju098.

17. Patel AV, Hildebrand JS, Campbell PT, et al. Leisure-time spent sitting and site-specific cancer incidence in a large U.S. cohort. Cancer Epidemiol Biomarkers Prev. 2015;24(9):1350-1359.

18. Shephard RJ, Futcher R. Physical activity and cancer: how may protection be maximized? Crit Rev Oncog. 1997;8(2-3):219-272.

19. WHO Expert Consultation. Appropriate body-mass index for Asian populations and its implications for policy and intervention strategies. Lancet. 2004;363(9403):157-163.

20. Wang J, Wu X, Kamat A, Barton Grossman H, Dinney CP, Lin J. Fluid intake, genetic variants of UDP-glucuronosyltransferases, and bladder cancer risk. Br J Cancer. 2013;108(11):2372-2380.

21. Wu M, Zhao J, Zhang Z, et al. Smoking and alcohol drinking increased the risk of esophageal cancer among Chinese men but not women in a high-risk population. Cancer Causes Control. 2011;22(4):649-657.

22. Blair SN, Cheng Y, Holder JS. Is physical activity or physical fitness more important in defining health benefits? Med Sci Sports Exerc. 2001;33(6 suppl):S379-S399.

23. Danaei G, Vander HS, Lopez AD, Murray CJ, Ezzati M; Comparative Risk Assessment collaborating group (Cancers). Causes of cancer in the world: comparative risk assessment of nine behavioural and environmental risk factors. Lancet. 2005;366(9499):1784-1793.

24. Moore SC, Lee I, Weiderpass E, et al. Association of leisure-time physical activity with risk of 26 types of cancer in 1.44 million adults. JAMA Intern Med. 2016;176(6):816.

25. Thomson CA, McCullough ML, Wertheim BC, et al. Nutrition and physical activity cancer prevention guidelines, cancer risk, and mortality in the women's health initiative. Cancer Prev Res (Phila). 2014; $7(1): 42-53$.

26. Parent M, Rousseau M, El-Zein M, Latreille B, Désy M, Siemiatycki J. Occupational and recreational physical activity during adult life and the risk of cancer among men. Cancer Epidemiol. 2011;35(2): 151-159.

27. Dar NA, Shah IA, Bhat GA, et al. Socioeconomic status and esophageal squamous cell carcinoma risk in Kashmir, India. Cancer Sci. 2013; 104(9):1231-1236.

28. Lee IM, Djousse L, Sesso HD, Wang L, Buring JE. Physical activity and weight gain prevention. JAMA. 2010;303(12):1173-1179.

29. Campbell KL, Foster-Schubert KE, Alfano CM, et al. Reduced-calorie dietary weight loss, exercise, and sex hormones in postmenopausal women: randomized controlled trial. J Clin Oncol. 2012;30(19): 2314-2326.

30. Ling ZQ, Mukaisho K, Yamamoto H, et al. Initiation of malignancy by duodenal contents reflux and the role of ezrin in developing esophageal squamous cell carcinoma. Cancer Sci. 2010;101(3):624-630.

31. Djärv T, Wikman A, Nordenstedt H, Johar A, Lagergren J, Lagergren P. Physical activity, obesity and gastroesophageal reflux disease in the general population. World J Gastroenterol. 2012;18(28):3710.

32. McTiernan A. Mechanisms linking physical activity with cancer. Nat Rev Cancer. 2008;8(3):205-211.

33. Friedenreich CM, Neilson HK, Lynch BM. State of the epidemiological evidence on physical activity and cancer prevention. Eur J Cancer. 2010;46(14):2593-2604.

34. Rogers CJ, Colbert LH, Greiner JW, Perkins SN, Hursting SD. Physical activity and cancer prevention: pathways and targets for intervention. Sports Med. 2008;38(4):271-296.

35. Dungan LS, McGuinness NC, Boon L, Lynch MA, Mills KH. Innate IFN-gamma promotes development of experimental autoimmune encephalomyelitis: a role for NK cells and M1 macrophages. Eur $J$ Immunol. 2014;44(10):2903-2917.

36. Martin-Fontecha A, Thomsen LL, Brett S, et al. Induced recruitment of NK cells to lymph nodes provides IFN-gamma for $\mathrm{T}(\mathrm{H}) 1$ priming. Nat Immunol. 2004;5(12):1260-1265. 
37. Idorn M, Hojman P. Exercise-dependent regulation of NK cells in cancer protection. Trends Mol Med. 2016;22(7):565-577.

38. Brown LM, Hoover R, Silverman D, et al. Excess incidence of squamous cell esophageal cancer among US Black men: role of social class and other risk factors. Am J Epidemiol. 2001;153(2):114-122.

39. Ma Z, Liu Y, Zhou X, et al. Research on stress-induced apoptosis of natural killer cells and the alteration of their killing activity in mouse liver. World J Gastroenterol. 2013;19(37):6258.

40. Shen D, Mao W, Liu T, et al. Sedentary behavior and incident cancer: a meta-analysis of prospective studies. PLoS One. 2014;9(8): e105709.

41. Balkau B, Mhamdi L, Oppert JM, et al; EGIR-RISC Study Group. Physical activity and insulin sensitivity: the RISC study. Diabetes. 2008; 57(10):2613-2618.

42. Gustat J, Srinivasan SR, Elkasabany A, Berenson GS. Relation of selfrated measures of physical activity to multiple risk factors of insulin resistance syndrome in young adults: the Bogalusa Heart Study. J Clin Epidemiol. 2002;55(10):997-1006.
43. Lindkvist B, Johansen D, Stocks T, et al. Metabolic risk factors for esophageal squamous cell carcinoma and adenocarcinoma: a prospective study of 580,000 subjects within the Me-Can project. BMC Cancer. 2014; $14: 103$.

44. Di Caro S, Cheung WH, Fini L, et al. Role of body composition and metabolic profile in Barrett's oesophagus and progression to cancer. Eur J Gastroenterol Hepatol. 2016;28(3):251-260.

45. Lynch BM. Sedentary behavior and cancer: a systematic review of the literature and proposed biological mechanisms. Cancer Epidemiol Biomarkers Prev. 2010;19(11):2691-2709.

46. van Kruijsdijk RC, van der Wall E, Visseren FL. Obesity and cancer: the role of dysfunctional adipose tissue. Cancer Epidemiol Biomarkers Prev. 2009;18(10):2569-2578.

47. Wang JB, Fan JH, Liang H, et al. Attributable causes of esophageal cancer incidence and mortality in China. PLoS One. 2012;7(8):e42281.

48. Wang Z, Tang L, Sun G, et al. Etiological study of esophageal squamous cell carcinoma in an endemic region: a population-based case control study in Huaian, China. BMC Cancer. 2006;6:287.
OncoTargets and Therapy

\section{Publish your work in this journal}

OncoTargets and Therapy is an international, peer-reviewed, open access journal focusing on the pathological basis of all cancers, potential targets for therapy and treatment protocols employed to improve the management of cancer patients. The journal also focuses on the impact of management programs and new therapeutic agents and protocols on

\section{Dovepress}

patient perspectives such as quality of life, adherence and satisfaction The manuscript management system is completely online and includes a very quick and fair peer-review system, which is all easy to use. Visit http://www.dovepress.com/testimonials.php to read real quotes from published authors. 